\title{
Failure Mechanism of 0-Ring Seals under Extreme Operating Conditions
}

\author{
György Szabó, Károly Váradi \\ Department of Machine and Product Design, Budapest University of Technology and Economics, Budapest, Hungary \\ Email: szabo.gyorgy@gt3.bme.hu
}

How to cite this paper: Szabó, Gy. and Váradi, K. (2018) Failure Mechanism of O-Ring Seals under Extreme Operating Conditions. Modern Mechanical Engineering, 8, 11-30.

https://doi.org/10.4236/mme.2018.81002

Received: November 10, 2017

Accepted: January 21, 2018

Published: January 24, 2018

Copyright $(9) 2018$ by authors and Scientific Research Publishing Inc. This work is licensed under the Creative Commons Attribution International License (CC BY 4.0).

http://creativecommons.org/licenses/by/4.0/

Open Access

\begin{abstract}
In this paper the behavior of an O-ring made of NBR rubber was investigated under extreme conditions. The effect of the extreme initial compression, operating pressure and extreme temperature conditions were examined. The rubber material was tested in simple tension, pure shear and equibiaxial tension modes complemented with a Dynamic Mechanical Thermal Analysis (DMTA) to capture the viscoelastic behavior of the material. For the investigation, a large-strain viscoelastic material model was developed by the authors, to take into account the large deformations caused by extreme conditions. Insufficient space during installation causes extreme initial compression consequently leading the material to crack on the contacting outer surfaces. It was found that the excessive strain and friction induced shear stress contributes primarily to this phenomenon. Extreme operating pressure causes the seal to penetrate into the gap between the shaft and the housing. This behavior damages the material and cracks appear on the seal. High strain areas were found in the proximity of the gap in the material. The analysis of the extreme operating temperature showed that during cooling the O-ring can completely loose its ability to seal at $-70^{\circ} \mathrm{C}$. There are three contributing factors: the speed of cooling, the temperature and the coefficient of thermal expansion.
\end{abstract}

\section{Keywords}

O-Rings, Finite Element Analysis, Initial Pressure, Overpressure, Temperature Extremes

\section{Introduction}

O-rings are one of the most widely used seals today. Their simple design, easy manufacturability and versatile functions made this type of seal to be used in broad range of industries like automotive-, shipping-, agricultural-, machinery-, 
energy-, and healthcare industry as well as in household appliances. Their operating principle follows: when compressing an elastomer material into a smaller space, it changes its' shape. During this procedure the material urges to restore its' original shape and as a result, force acts on the contacting surfaces, contact pressure is developing. This is called preload. This preload is important when the operating pressure is not acting, so that the system is sealed initially. After operating pressure is applied, as the rubber material is nearly incompressible, it transfers the operating pressure to the surrounding surfaces, increasing the initial contact pressure. This self-sealing effect makes O-rings to be an effective, economical yet simple type of seal.

O-rings normally operate between $-40^{\circ} \mathrm{C}$ and $+80^{\circ} \mathrm{C}$, and used up to 50 bars of pressure. These values greatly depend on the rubber material as well as the design of the seal, e.g. usage of back-up rings and the operating conditions such as static or dynamic mode. This article focuses on the extremities O-rings can experience during their operation. During assembly an unsuitable groove design can force the material into smaller space than required, compressing the material too much initially, which leads to cracks to appear on the contacting sides on the circumference of the O-ring as depicted in Figure 1(a) [1]. Figure 1(b) shows the failure of the O-ring due to faulty assembly. During the assembly process, the shaft and the housing can shear off material from the seal, resulting immediate leakage [1] [2]. Figure 1(c) shows another typical form of fail, when the material extrudes into the gap between the shaft and the housing. This extrusion can occur as a consequence of excessive temperature, as the material softens at high temperatures, excessive operating pressure, losing the ability to withstand high forces, too large gap between the parts, and even swelling of the material due to chemical processes [1] [2]. The behavior of O-rings was analyzed in harsh operating conditions: in very high initial compression, high operating pressures, and in extreme low temperatures down to $-80^{\circ} \mathrm{C}$.

\section{Characterization of the NBR Rubber Material}

\subsection{Experiments}

For the rubber material characterization, different extension tests and dynamic tests were performed. Namely simple tension, pure shear and equal biaxial tests

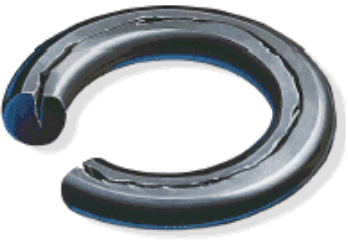

(a)

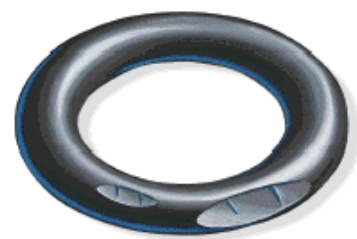

(b)

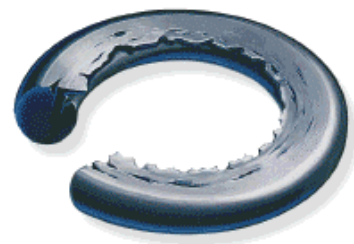

(c)

Figure 1. Different failure modes of O-rings due to extreme conditions [1] (a) circumferential cracks caused by excessive initial compression; (b) sheared off surface of the O-ring due to faulty assembly; (c) extrusion of the O-ring caused by excessive operating pressure, excessive temperature or too large gap between the shaft and the housing. 
were carried out, followed by a Dynamic Mechanical Thermal Analysis (DMTA) test. The rubber material of the O-ring is NBR70 K55, which means, that the material has a hardness of 70 on a Shore A hardness scale, and its' glass transition temperature is around $-55^{\circ} \mathrm{C}$. The simple tension test was performed according to ISO 37 international standard [3]. For the pure shear test custom made test specimen and grips were used. The equal biaxial tests were carried out by the Institute of Polymer Product Engineering at Johannes Kepler University in Linz, with a custom made biaxial device [4]. The engineering stress and strain data obtained by the equal biaxial extension test were then converted into engineering stress and strain data in uniaxial compression mode. The reason for doing so was, that the results of the uniaxial compression tests depend greatly on the coefficient of friction between the compression test specimen and the surface of the specimen grips [5]. Applying lubricant on the aforementioned surfaces can reduce the uncertainty of the measurement, but especially at high compressive strains the effect of friction is inevitable. It was the authors' intention to reduce the amount of uncertainty caused by measurement error, thus the usage of equal biaxial test data. The conversions between equal biaxial and uniaxial compression in terms of stress and strain are the following [6]:

$$
\begin{aligned}
& \varepsilon_{\text {comp }}=1 /\left(1+\varepsilon_{\text {biax }}\right)^{2}-1 \\
& \sigma_{\text {comp }}=\sigma_{\text {biax }}\left(1+\varepsilon_{\text {biax }}\right)^{3}
\end{aligned}
$$

The speed of extension in all strain states was $100 \mathrm{~mm} / \mathrm{s}$. Zwick Z020 universal tensile tester was used for uniaxial tension and pure shear tests with Test Xpert II measurement software. Figure 2 illustrates the shape and dimensions of the tests specimens. Figure 3 and Figure 4 show the engineering and true stress-strain curves obtained by extension tests.

DMTA test was performed in order to capture the rubber's viscoelastic behavior. The test was carried out in tension mode on a GABO EPLEXOR $500 \mathrm{~N}$ measuring device. During the test, rectangular specimen is stretched by a static load and then a sinusoidal dynamic load is superimposed on it. The static and

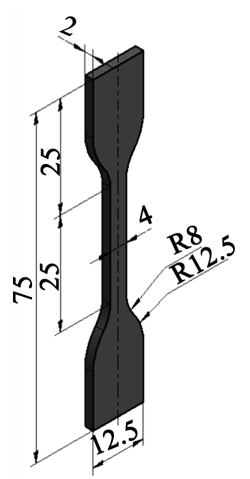

(a)

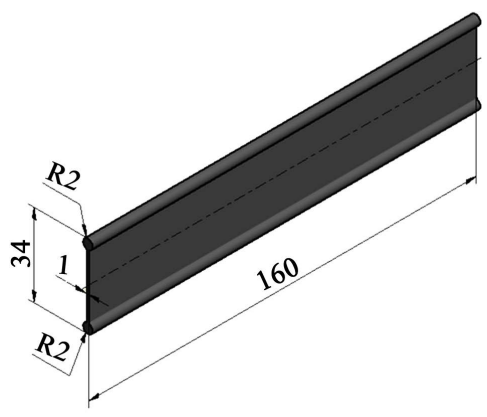

(b)

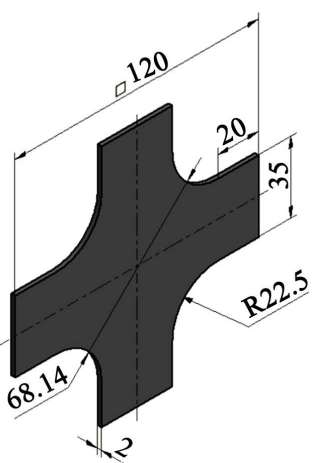

(c)

Figure 2. Shape and dimensions of the tensile, pure shear and equal biaxial test specimens. 


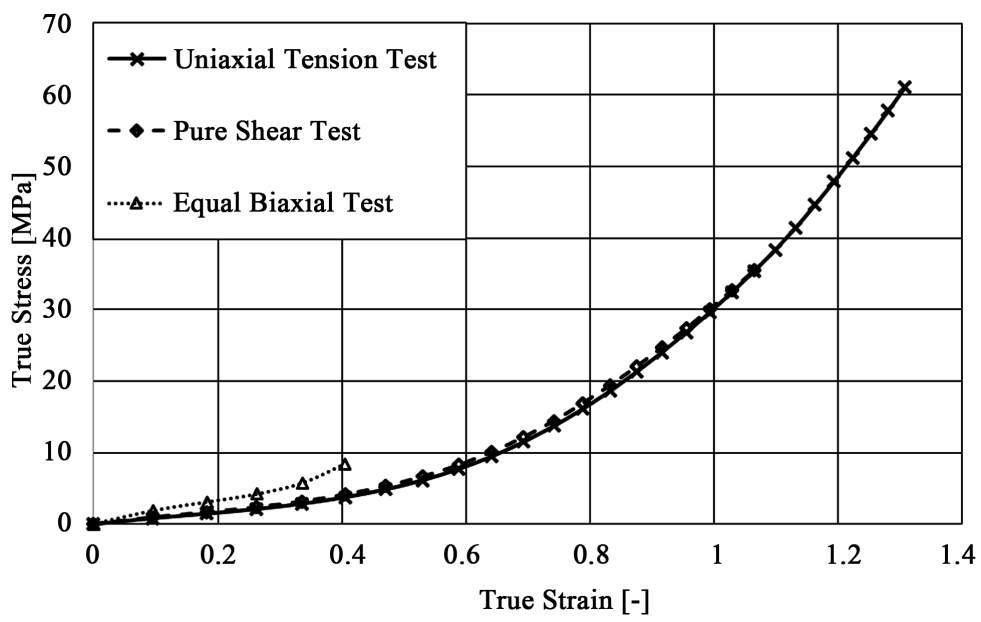

Figure 3. The obtained engineering stress vs. engineering strain curves of NBR70 rubber material for different strain states.

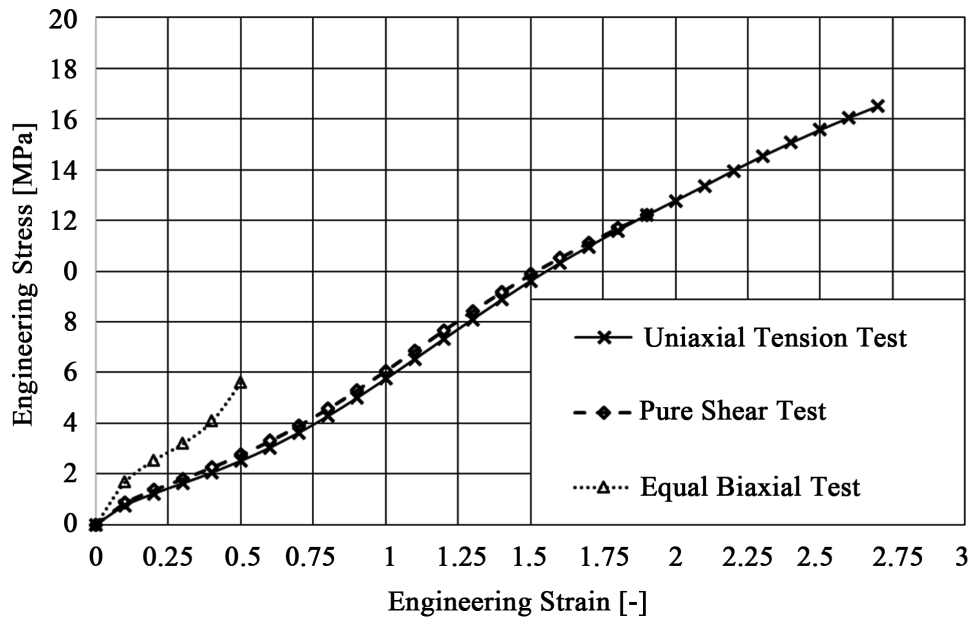

Figure 4. The obtained true stress vs. true strain curves of NBR70 rubber material for different strain states.

dynamic load as an excitation is not in phase with the reaction force developed in the rubber [7]. This phase shift characterizes the viscoelastic response of the rubber. During this analysis the machine measures the storage modulus ( $\left.E^{\prime}\right)$, the loss modulus ( $\left.\mathrm{E}^{\prime \prime}\right)$, the complex modulus $\left(\mathrm{E}^{*}\right)$ and the loss factor $(\tan \delta)$ of the material. The rectangular cross section of the specimen was $5.96 \mathrm{~mm}$ by 1.79 $\mathrm{mm}$, the distance between the clamps was $20 \mathrm{~mm}$. The test was carried out from $-100^{\circ} \mathrm{C}$ to $+80^{\circ} \mathrm{C}$ with $4^{\circ} \mathrm{C}$ temperature steps. At each temperature the specimen was excited with 15 different frequencies from $0.2 \mathrm{~Hz}$ to $60 \mathrm{~Hz}$ with $4.27 \mathrm{~Hz}$ frequency steps. The preload of the test specimen was $2 \mathrm{~N}$, and the distance between the tensile specimen grips was recorded. These recorded data then served as the basis of the applied loads. The static load was $1 \%$, the dynamic load was $0.1 \%$ strain of the measured distances between the clamps at each measurement point. The reason to use preload was to compensate the deformation of the specimen caused by the tightening of the clips and to compensate the material's 
thermal expansion and creep, thus to enhance the precision of the measurement. At each temperature the soak time was set to $600 \mathrm{~s}$. Figure 5 shows the E' storage modulus and $\tan \delta$ loss factor as results of the measurement.

\subsection{Material Model}

For the finite element analysis a large-strain viscoelastic material model was developed. The graphical representation of this model is shown in Figure 6. It consists of a spring and a series of spring and dashpot elements connected in parallel with each other. The complete process of the parameter identification is presented in the authors' previous article [8]. As a result Figure 7 shows the material model's response in terms of the storage modulus, loss modulus and loss factor.

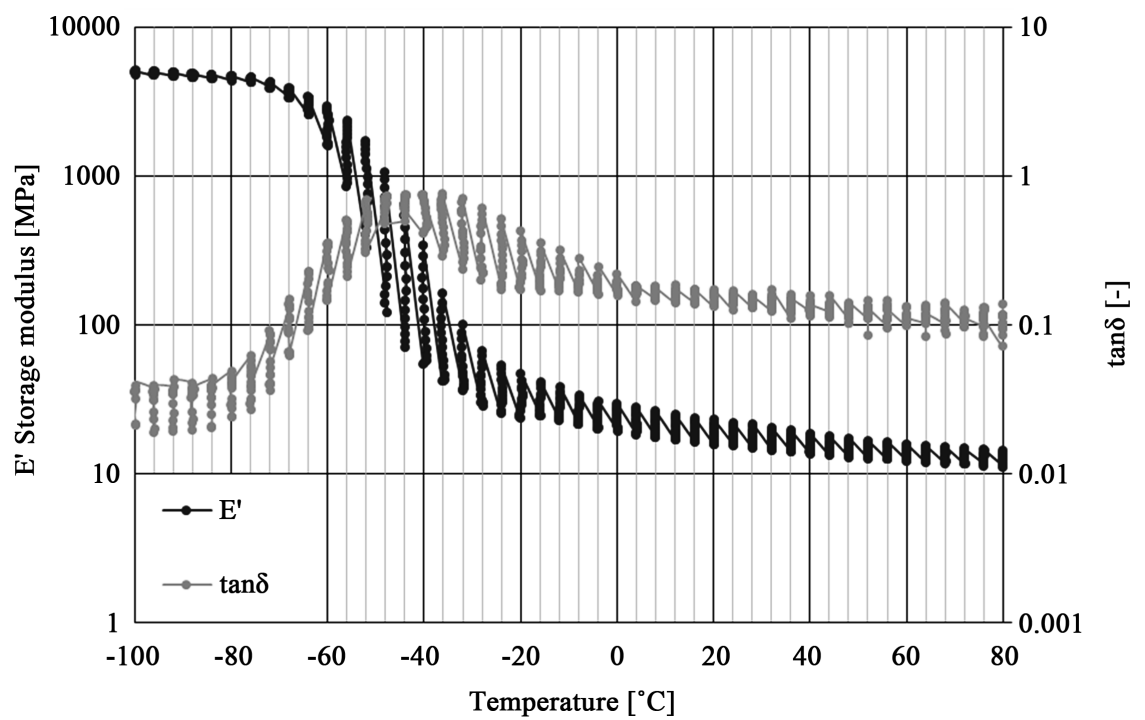

Figure 5. The measured storage modulus $\left(\mathrm{E}^{\prime}\right)$ and loss factor $(\tan \delta)$ of NBR 70 rubber material.

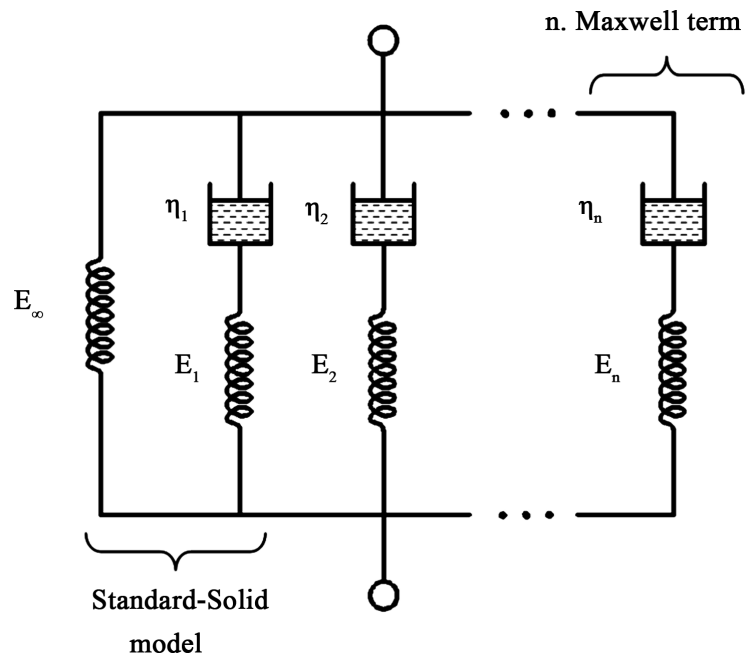

Figure 6. Graphical representation of the generalized standard-solid model. 


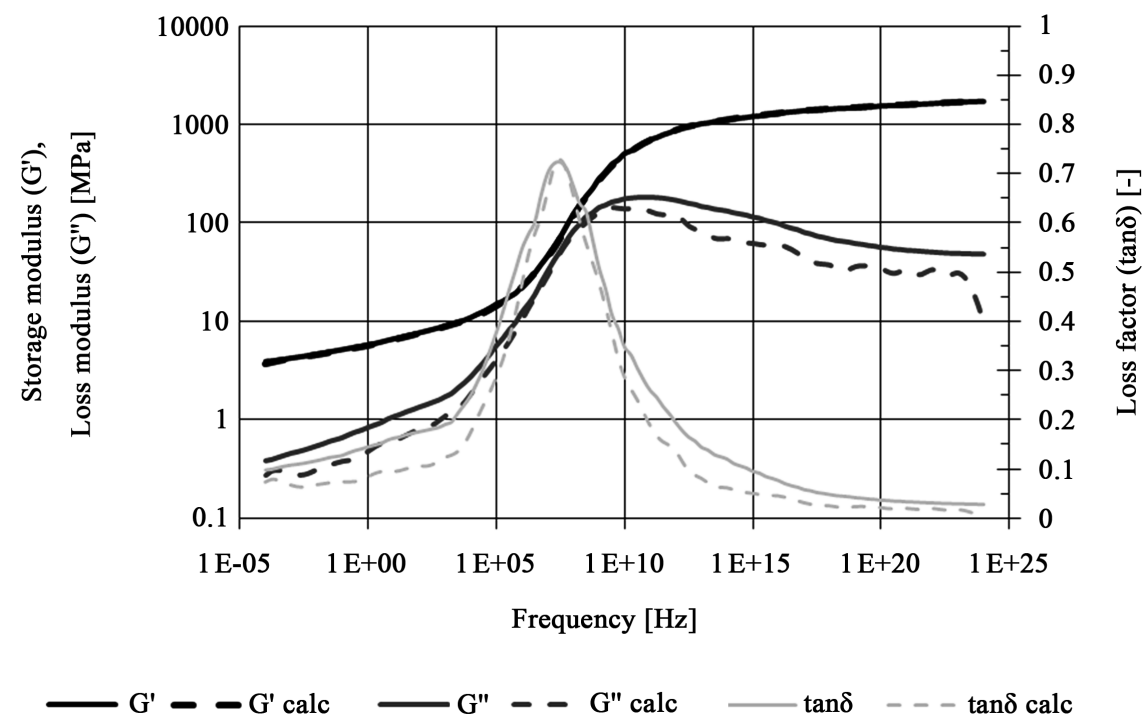

Figure 7. Comparison of the measured and the calculated response of the NBR70 rubber material.

\subsection{Verification of the Material Model}

To verify the developed material model FE simulations were performed for the three extension tests. The modelled specimen's dimensions are in accordance with the ones seen in Figure 2. For the finite element simulation 1/8-th of the test specimens were modeled to reduce computational time. The tensile speed in all three cases was $100 \mathrm{~mm} / \mathrm{s}$. Figure 8 shows the applied constrains and displacement loads (marked with black arrow) on the modelled 1/8-th test specimens. One can see the specimens were constrained with frictionless supports on its' planes of symmetry. On the sides where the displacement loads were applied, the side could only move in the direction of displacement, marked with arrows in Figure 8. On the free edges no constrain was applied.

Figure 9 shows the response of the material model compared to the measured data in uniaxial tension, pure shear and equal biaxial strain states. It can be seen that a material model shows good correlation with the measured values in each strain state but especially in uniaxial tension and pure shear modes. The model can accurately follow the rubber's behavior up to $150 \%$ engineering strain. This is important because high strain values are expected during extreme operating conditions due to overload and high temperature. The precise material model is required to gain good results from the FE simulation. Without having a material model fitted in all above mentioned three strain states, the results could not be justified when the material is in a complex strain state. Thus the importance of fitting the material model to all strain states that are experimentally available.

\section{Finite Element Models}

\subsection{FE model for Extreme Initial Compression Case}

For the analysis of the effect of the extreme initial compression, an axisymmetric 


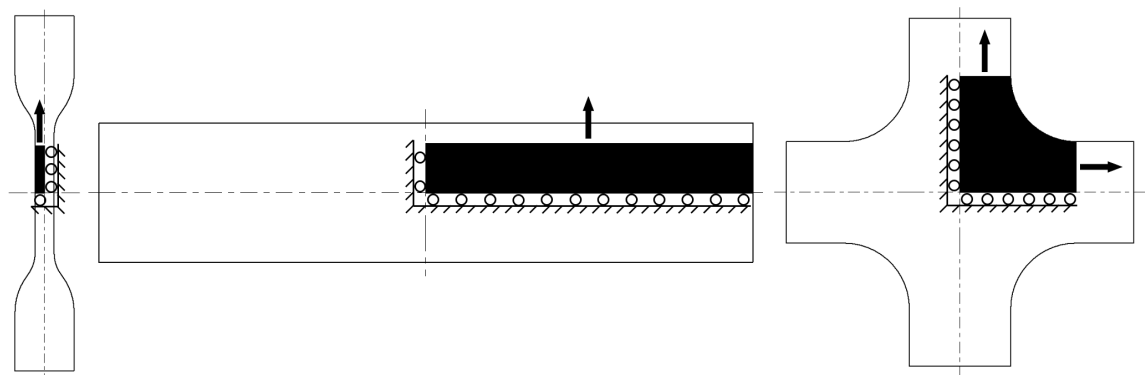

Figure 8. Specimens used to verify the material models in uniaxial tension, pure shear and equal biaxial tension modes.

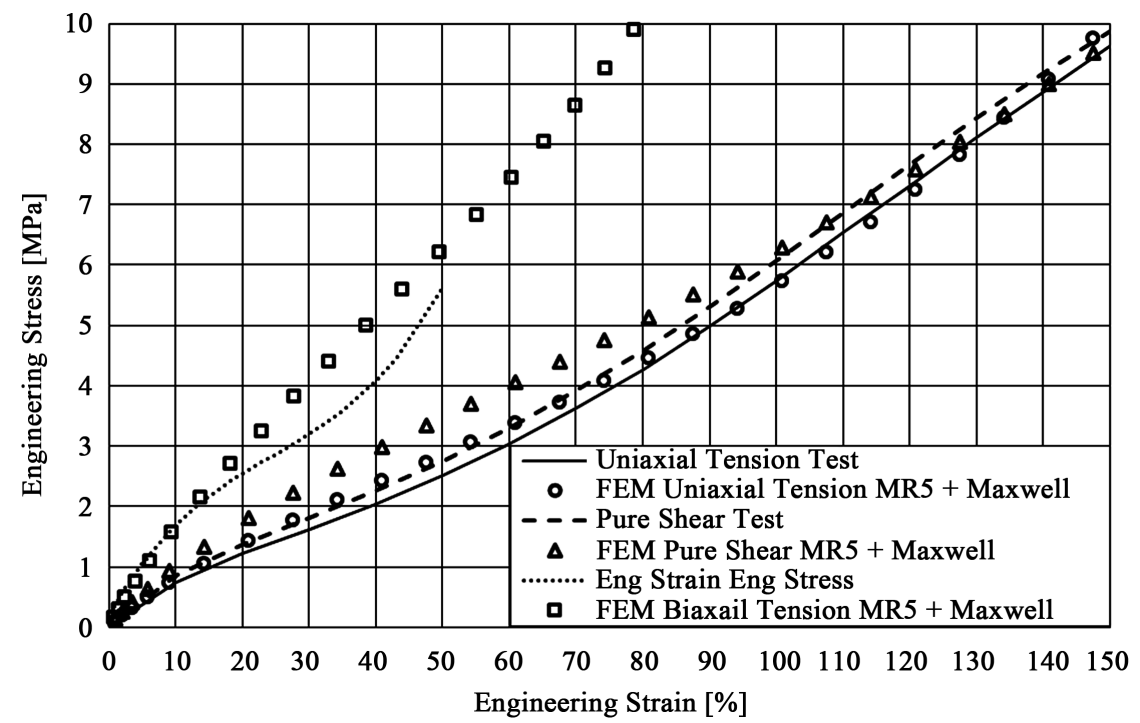

Figure 9. Comparison of the large-strain viscoelastic material model with the rubber's response in uniaxial tension, pure shear, and equal biaxial modes.

FE model was built. The model consists of three bodies, namely the O-ring, the housing and the pipe-like shaft. The reason of the axisymmetric model and the use of a hollow shaft, was to reduce the total number of elements, thus reduce computational time. The dimensions of the original geometry was presented in the authors' previous article [8].

Compared to that, the pipe-like shaft was modified to have a $2 \mathrm{~mm} \times 15^{\circ}$ chamfer on the inner edge, to enhance convergence when simulating the assembling process. Furthermore, the depth of the groove, where the O-ring is located, was parameterized, so that higher initial compression of the O-ring could be achieved. 15\%, 20\%, 30\% and 40\% of initial compression were analysed. Figure 10 shows the FE geometry for $15 \%$ and $40 \%$ of initial compression case.

Figure 11 shows the mesh of the model. Quadratic and triangular axisymmetric elements were used. The average element size $0.05 \mathrm{~mm}$ for the O-ring, 0.35 $\mathrm{mm}$ for the shaft, and $0.5 \mathrm{~mm}$ for the housing. Local mesh refinements were used on the inner edge of the shaft and the groove of the housing, where the elements size is $0.1 \mathrm{~mm}$. The effect of coefficient of friction between the bodies was also investigated for this simulation. First, the simulations were set up 

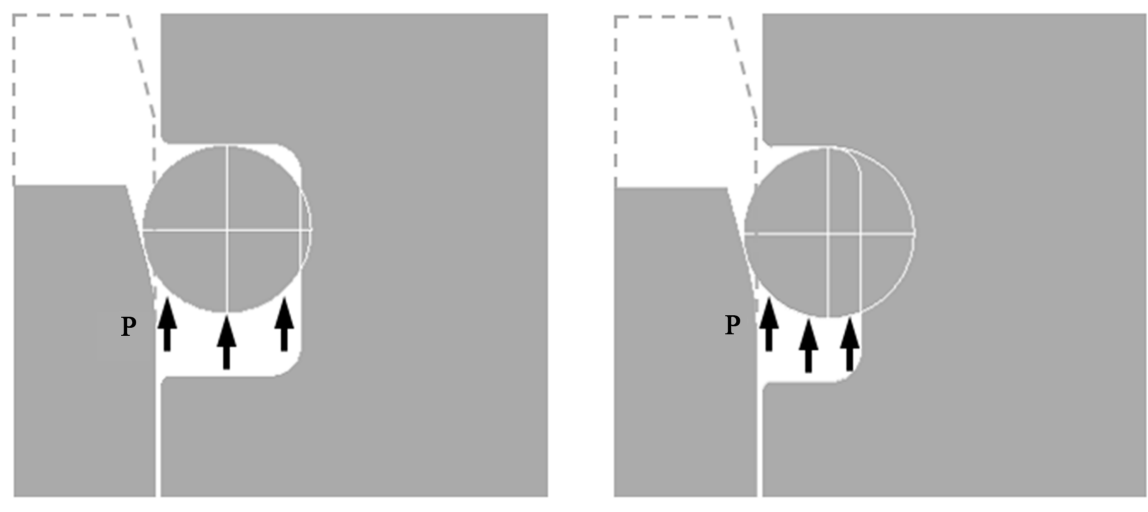

Figure 10. FE model of the O-ring before assembly for extreme initial pressure investigation, with $15 \%$ and $40 \%$ initial compression.
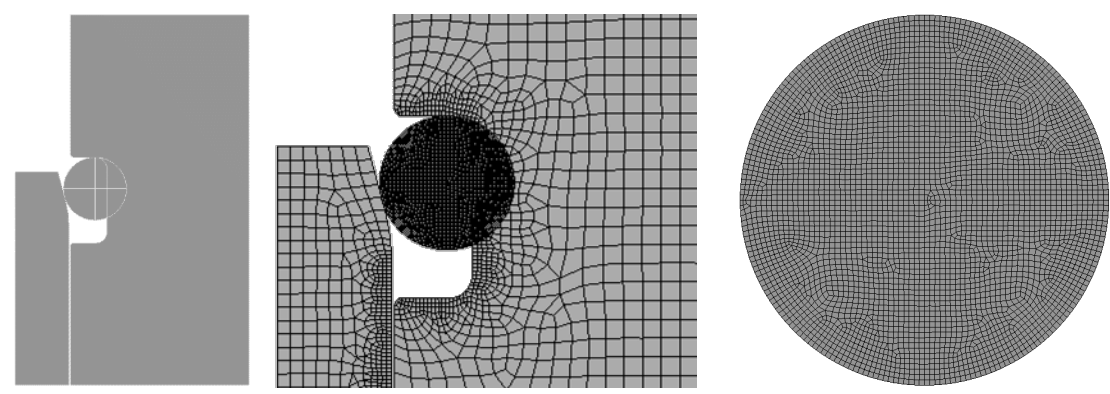

Figure 11. Mesh of the O-ring before assembly for $40 \%$ initial compression case.

without friction between the bodies $(\mu=0.001)$, then $\mu=0.1$ and $\mu=0.2$ were set. The contact technology used for the connections between the parts was Augmented Lagrange with aggressive, automatic normal contact stiffness update. During the analysis the shaft was moved upwards $4 \mathrm{~mm}$. The simulations were carried out in ANSYS Workbench 17.2 software [9].

\subsection{FE model for Extreme Pressure and Extreme Temperature Cases}

The FE model for extreme pressure case is identical to the one presented in [8]. Only the operation load was increased from 50 bars to 100 bars for extreme pressure case. The FE model for the extreme temperature case is similar to the above mentioned model, but the hollow shaft was replaced and a solid shaft was modelled. The effect of extreme temperature was investigated at different cooling speeds. First the available time for the seal to cool down was set to 1 hour, then 10 minutes, 1 minute and 10 seconds cooling times were investigated.

\section{Finite Element Results of the 0-Ring during Extreme Conditions}

All the results in this article are presented in a deformation scale 1:1.

\subsection{Effect of Initial Compression}

During the investigation of the initial pressure, different initial compression of 
the O-ring and different coefficient of friction were analysed. One can expect, that high initial compression causes cracks to appear on the contacting surface of the O-ring. Unlubricated conditions, where the coefficient of frictions is high, can aggravate the appearance of cracks. Because the $40 \%$ initial compression case with $\mu=0.2$ coefficient of friction is the worst case scenario, the deformation, strain and stress results are only presented to that case. Figure 12(a) and Figure 13(a), show the $\varepsilon_{1}$, and $\varepsilon_{3}$ principal strain values after installations, Figure 12(b) and Figure 13(b), illustrate the case right after the operating pressure is applied and Figure 12(c) and Figure 13(c), depict the case 1 hour after operating pressure is applied. Figures $14-16$, show the $\varepsilon_{\mathrm{X}}, \varepsilon_{\mathrm{Y}}$ and strain $\varepsilon_{\mathrm{Z}}$ values, while Figures 17-19 depict $\sigma_{\mathrm{X}}, \sigma_{\mathrm{Y}}$ and $\sigma_{\mathrm{Z}}$ stress values for the aforementioned cases. In Figure 20 one can see, the resulting equivalent elastic true strain. It can clearly be seen that the O-ring fills the groove completely, and right after assembly high strain areas occur in the middle of the O-ring, on the side of the O-ring,

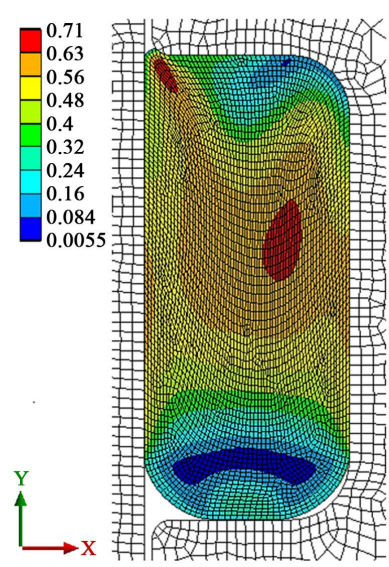

(a)

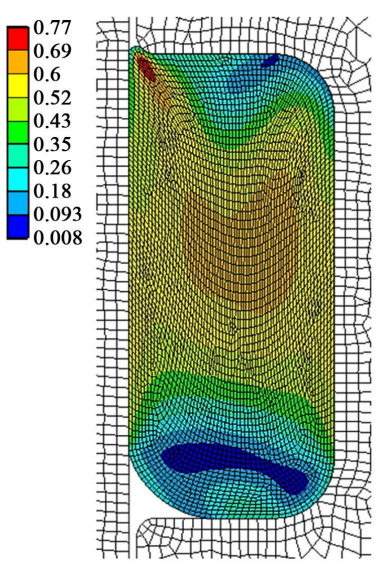

(b)

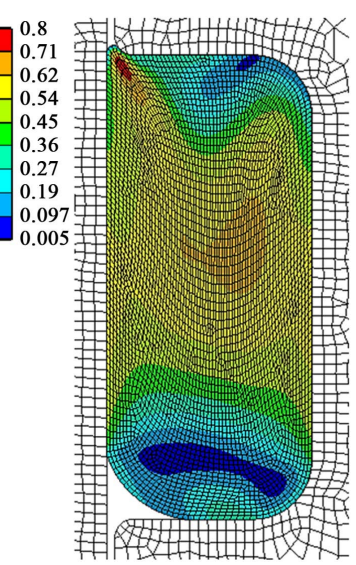

(c)

Figure 12. $\varepsilon_{1}$ results of the O-ring with $40 \%$ initial compression (a) after assembly; (b) after operating pressure is applied and (c) after 1 hour of operating pressure is applied.

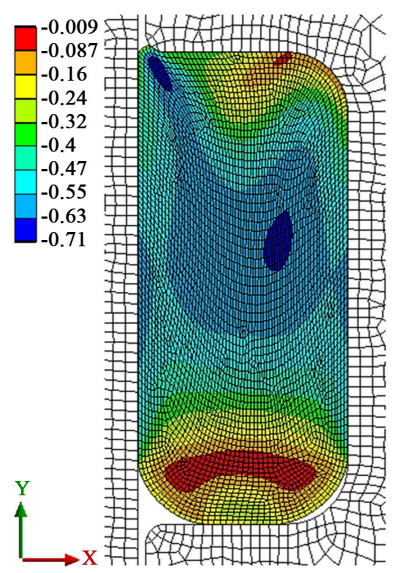

(a)

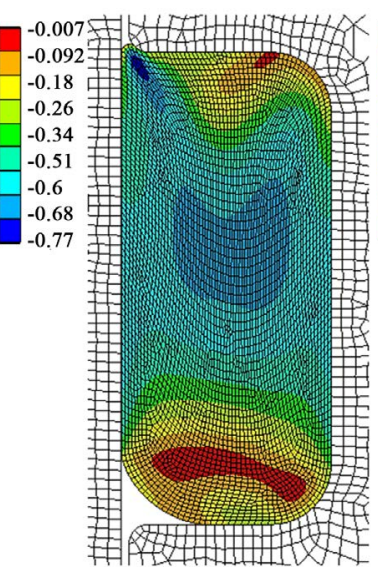

(b)

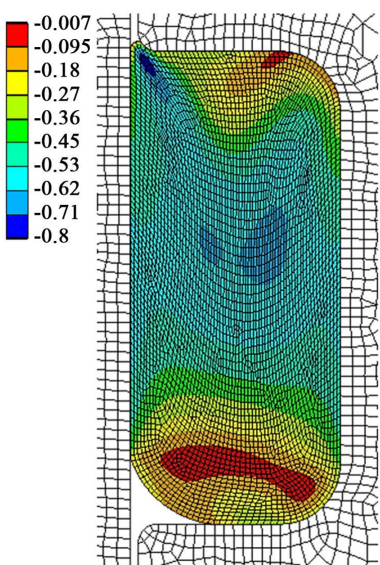

(c)

Figure 13. $\varepsilon_{3}$ results of the O-ring with $40 \%$ initial compression (a) after assembly; (b) after operating pressure is applied and (c) after 1 hour of operating pressure is applied. 


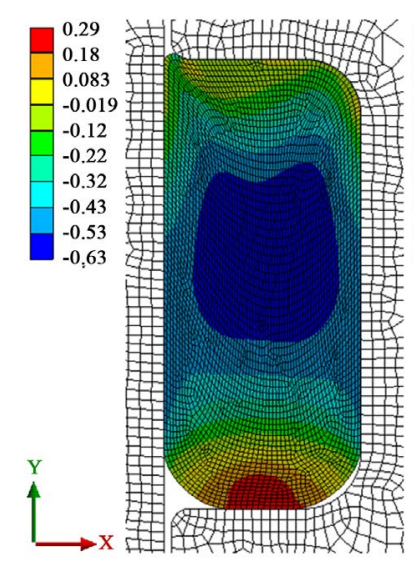

(a)

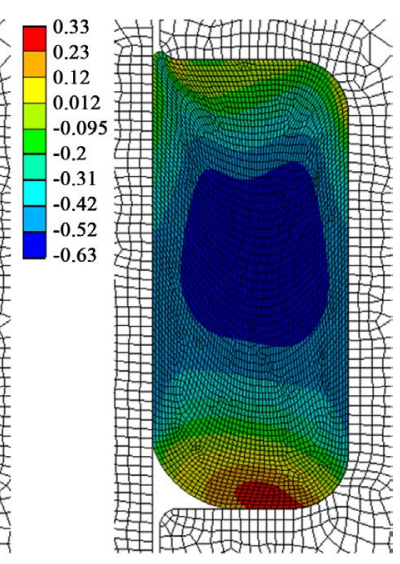

(b)

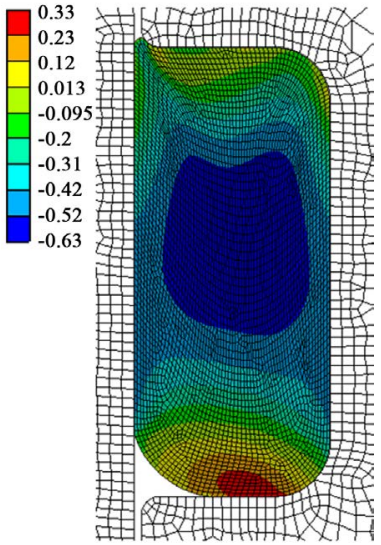

(c)

Figure 14. $\varepsilon_{\mathrm{X}}$ results of the O-ring with $40 \%$ initial compression (a) after assembly; (b) after operating pressure is applied and (c) after 1 hour of operating pressure is applied.

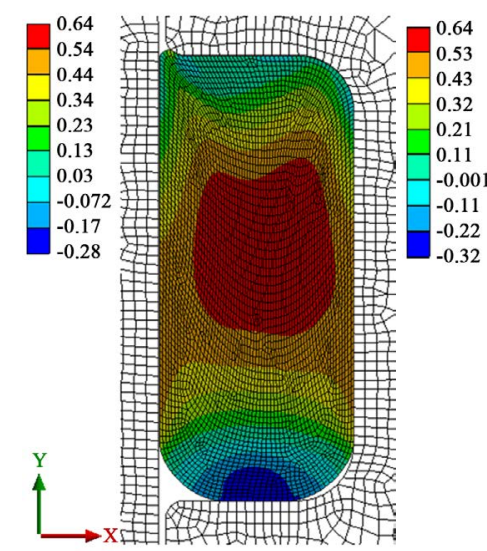

(a)

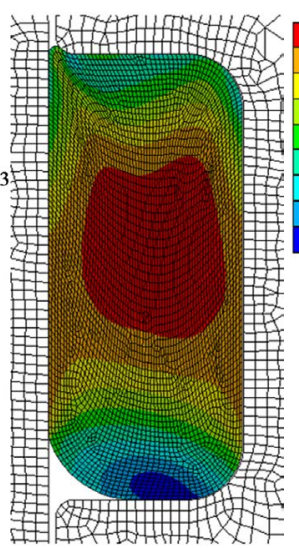

(b)

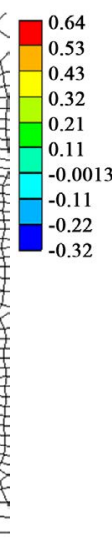

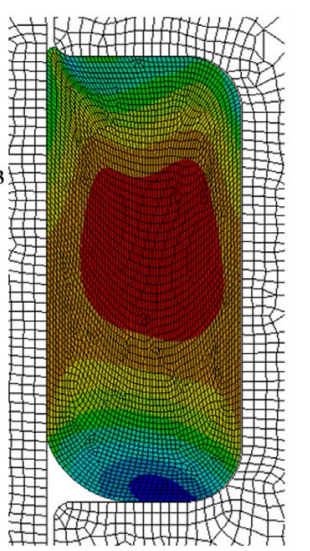

(c)

Figure 15. $\mathcal{E}_{\mathrm{Y}}$ results of the O-ring with $40 \%$ initial compression (a) after assembly; (b) after operating pressure is applied and (c) after 1 hour of operating pressure is applied.

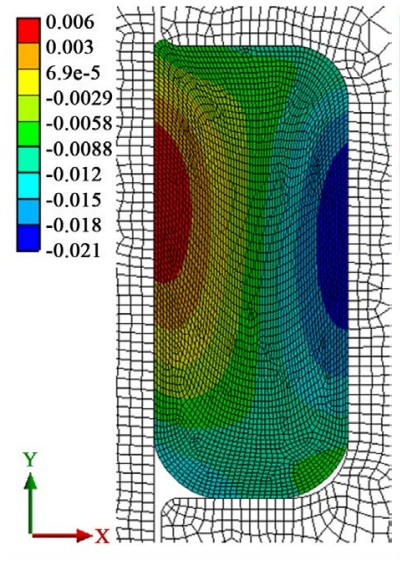

(a)

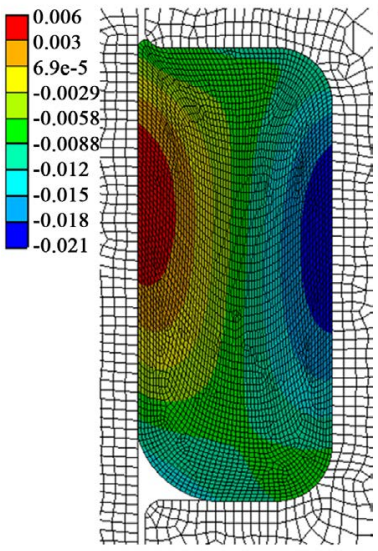

(b)

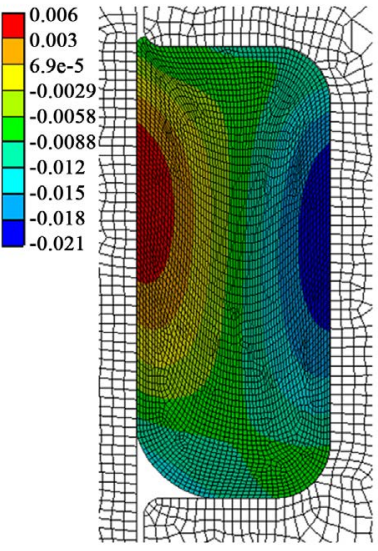

(c)

Figure 16. $\varepsilon_{\mathrm{Z}}$ results of the O-ring with $40 \%$ initial compression (a) after assembly; (b) after operating pressure is applied and (c) after 1 hour of operating pressure is applied. 


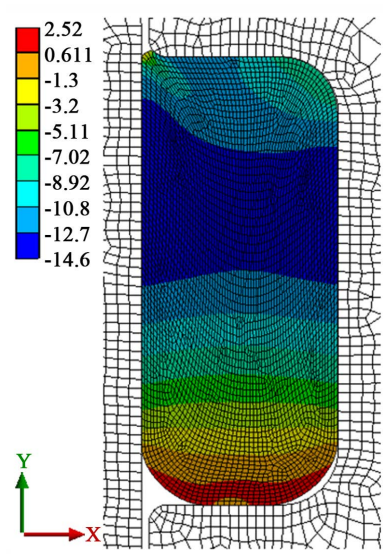

(a)

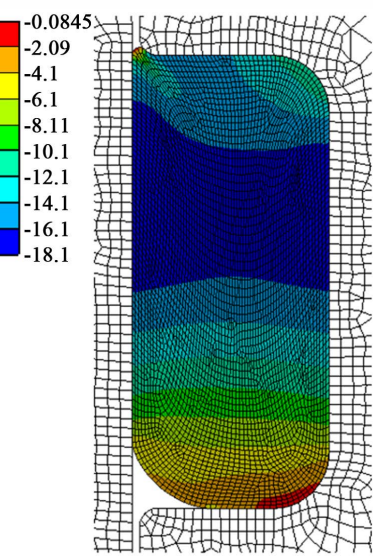

(b)

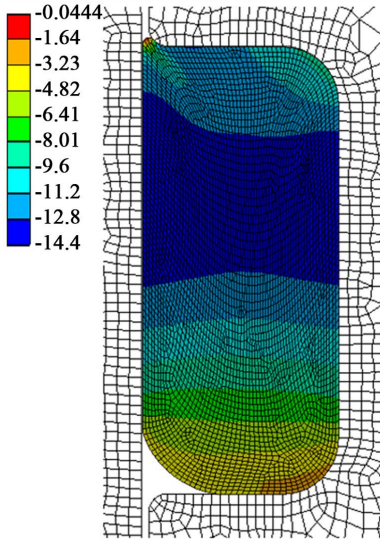

(c)

Figure 17. $\sigma_{\mathrm{X}}$ results of the O-ring with $40 \%$ initial compression (a) after assembly, (b) after operating pressure is applied and (c) after 1 hour of operating pressure is applied.

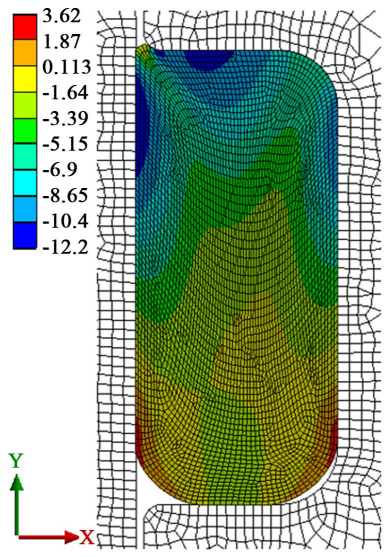

(a)

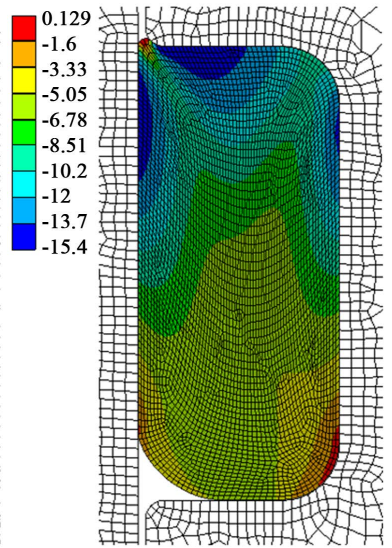

(b)

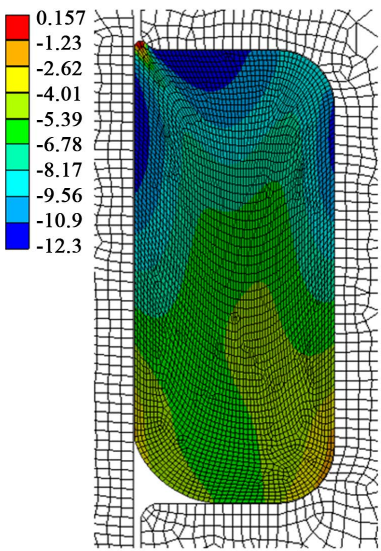

(c)

Figure 18. $\sigma_{\mathrm{Y}}$ results of the O-ring with $40 \%$ initial compression (a) after assembly; (b) after operating pressure is applied and (c) after 1 hour of operating pressure is applied.

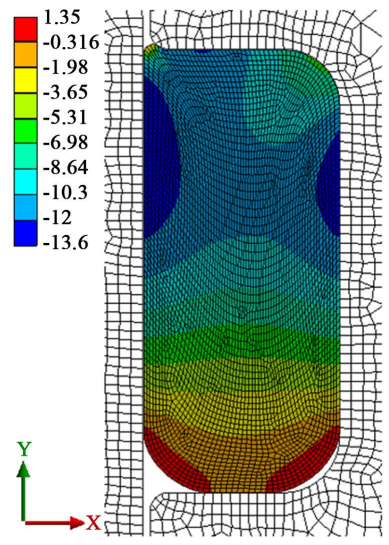

(a)

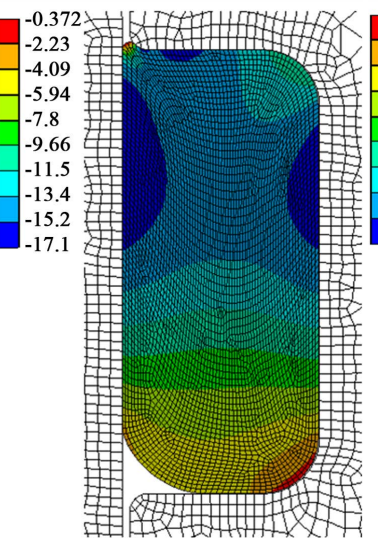

(b)

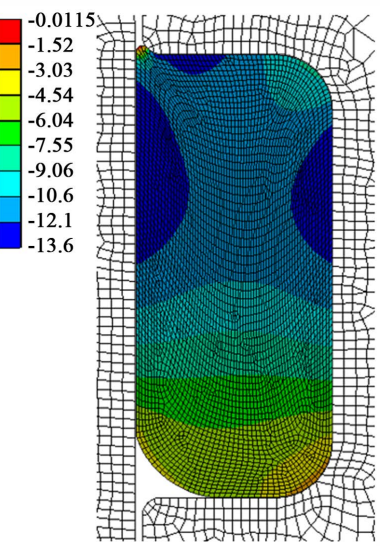

(c)

Figure 19. $\sigma_{\mathrm{Z}}$ results of the O-ring with $40 \%$ initial compression (a) after assembly; (b) after operating pressure is applied and (c) after 1 hour of operating pressure is applied. 


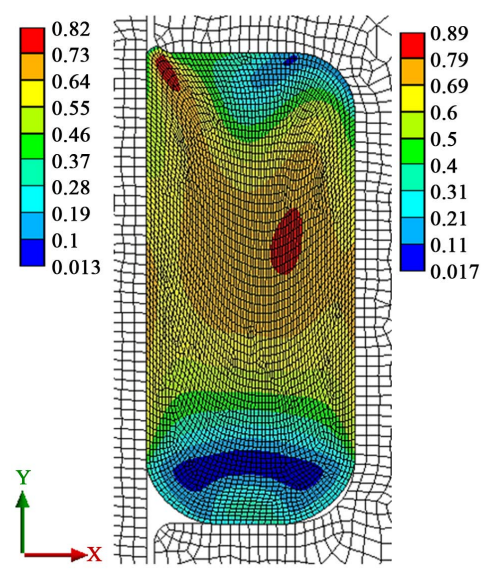

(a)

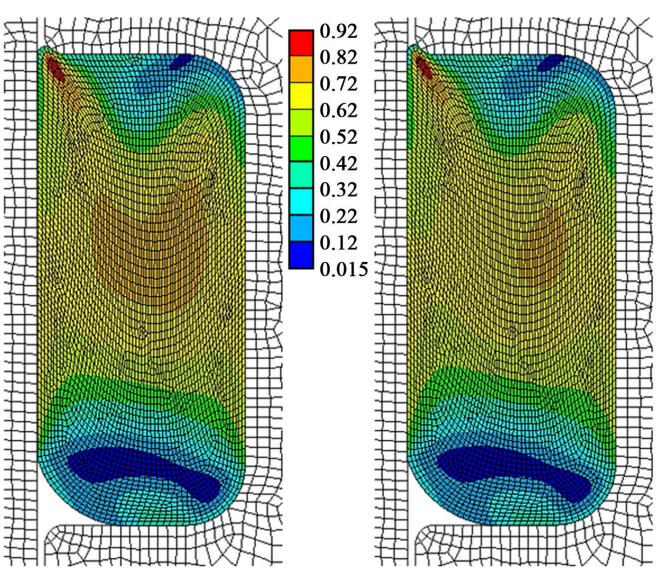

(b)

(c)

Figure 20. Equivalent elastic true strain results of the O-ring with $40 \%$ initial compression (a) after assembly; (b) after operating pressure is applied and (c) after 1 hour of operating pressure is applied.

where it is in contact with the housing and the shaft and where the material penetrates between the gap of the housing and the shaft. The results show that $\varepsilon_{1}$ and $\varepsilon_{3}$ are the dominant principal strain components. The maximal value of the equivalent elastic true strain for $40 \%$ initial compression is $0.82 \mathrm{~mm} / \mathrm{mm}$ after assembly and $0.92 \mathrm{~mm} / \mathrm{mm}$ after applying the operating pressure for 1 hour. The same parameters for $15 \%$ initial compression, which is a typical value for this type of O-ring are $0.2 \mathrm{~mm} / \mathrm{mm}$ after assembly and $0.42 \mathrm{~mm} / \mathrm{mm}$ after applied operating pressure. One can see, that for $40 \%$ initial compression, the values greatly exceed the values for normal operating conditions.

\section{Effect of Friction on Shear and Sealing Pressure}

Analysing the friction induced shear stress values of the inner and the outer edge of the O-ring where it is contacting with the housing and the shaft, it can be seen in Figures 21-23 that the shear stress values increase with increasing coefficient of friction. The distribution of shear stress along the edges is nearly symmetrical, only the presence of the gap alters the results, as the material can deform more on the side of the gap. Summarizing the shear stress and equivalent elastic strain results occurring on the edges, one can see in Figure 24, that the increasing initial compression and the ascending coefficient of friction increases the maximal value of the occurring shear stress. Figure 25 shows that beside the increasing shear stress the occurring equivalent elastic strain values also increase significantly on the edge of the O-ring. The higher strain and shear stress values can cause the material to develop cracks on its' outer edge when too high initial compression is applied.

In Figures 26-28 one can see the distribution of the contact pressure between the O-ring and the contacting parts. The contact pressure is zero on the non-contacting elements. It is seen, that with increasing coefficient of friction, the contact pressure values also increase. 


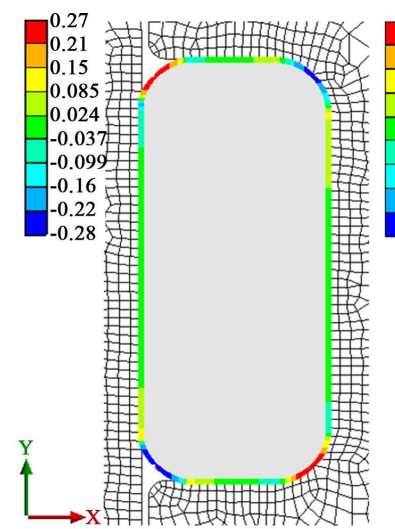

(a)

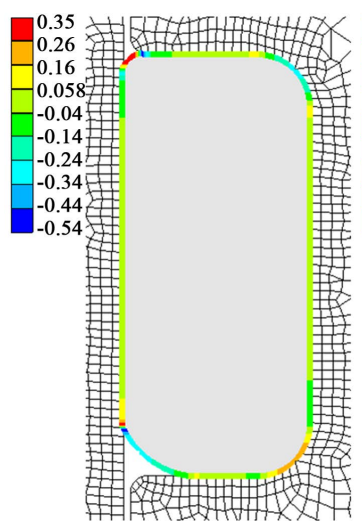

(b)

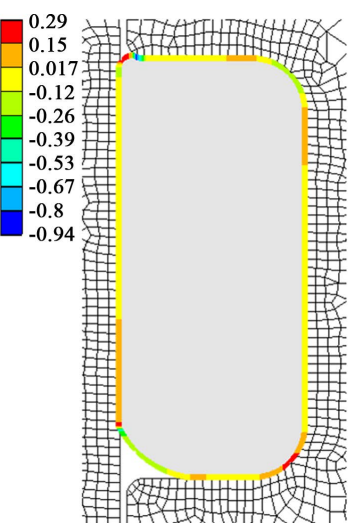

(c)

Figure 21. Shear stress in XY plane on the edge of the O-ring with $40 \%$ initial compression and $\mu=0.001$. (a) after assembly; (b) after operating pressure is applied and (c) after 1 hour of operating pressure is applied.

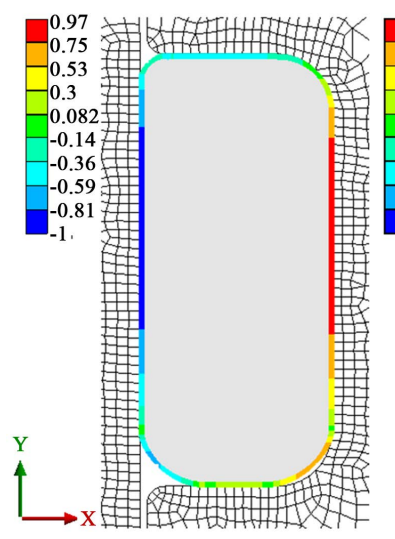

(a)

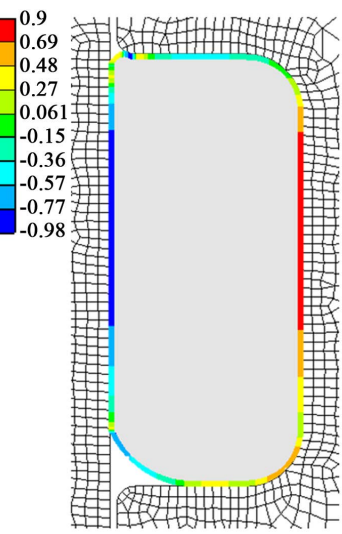

(b)

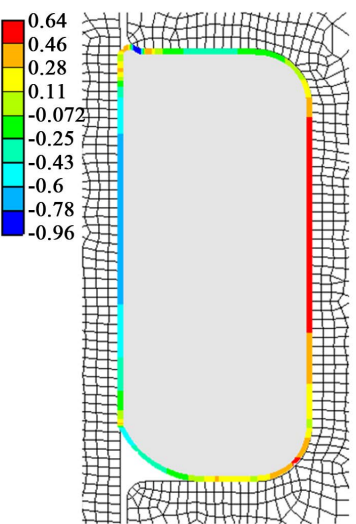

(c)

Figure 22. Shear stress in XY plane on the edge of the O-ring with $40 \%$ initial compression and $\mu=0.1$. (a) after assembly; (b) after operating pressure is applied and (c) after 1 hour of operating pressure is applied.

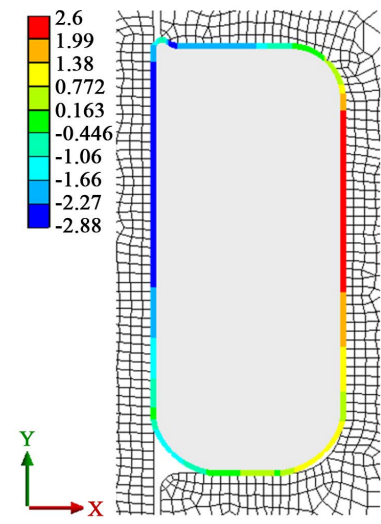

(a)

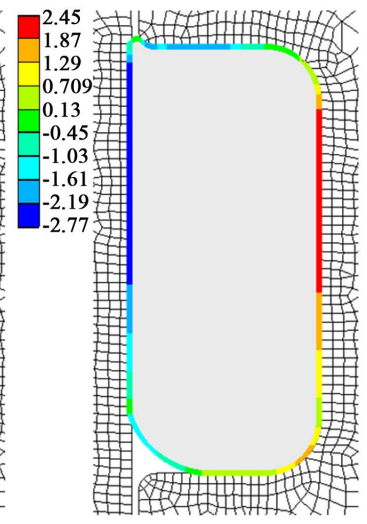

(b)

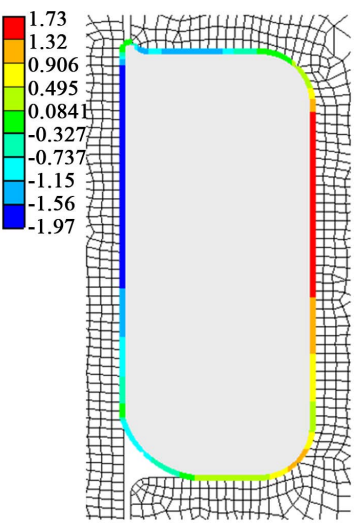

(c)

Figure 23. Shear stress in XY plane on the edge of the O-ring with $40 \%$ initial compression and $\mu=0.2$. (a) after assembly; (b) after operating pressure is applied and (c) after 1 hour of operating pressure is applied. 


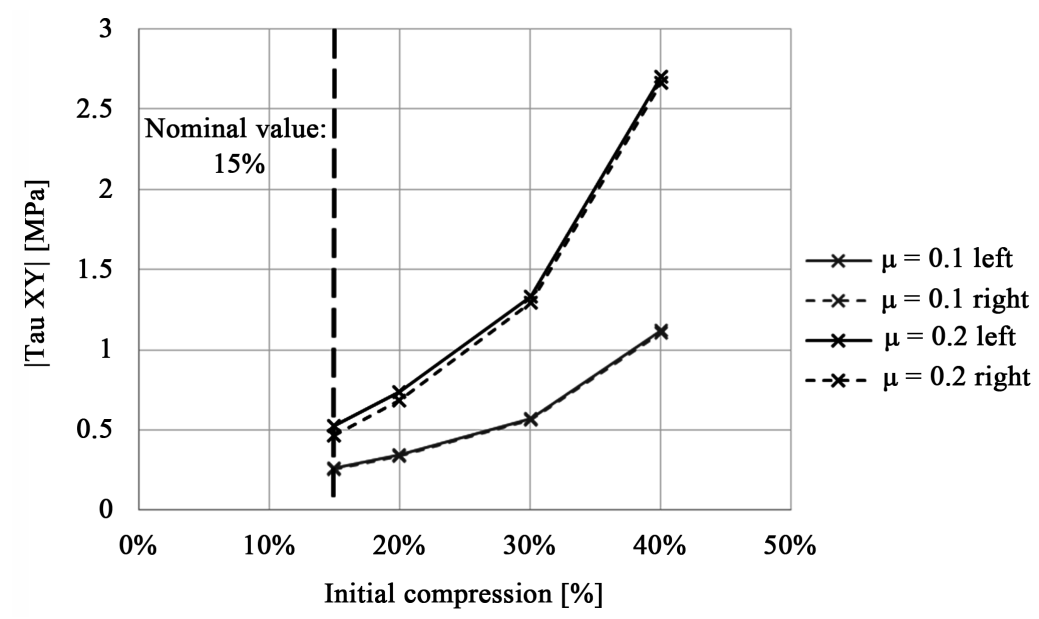

Figure 24. The shear stress in function of the initial compression.

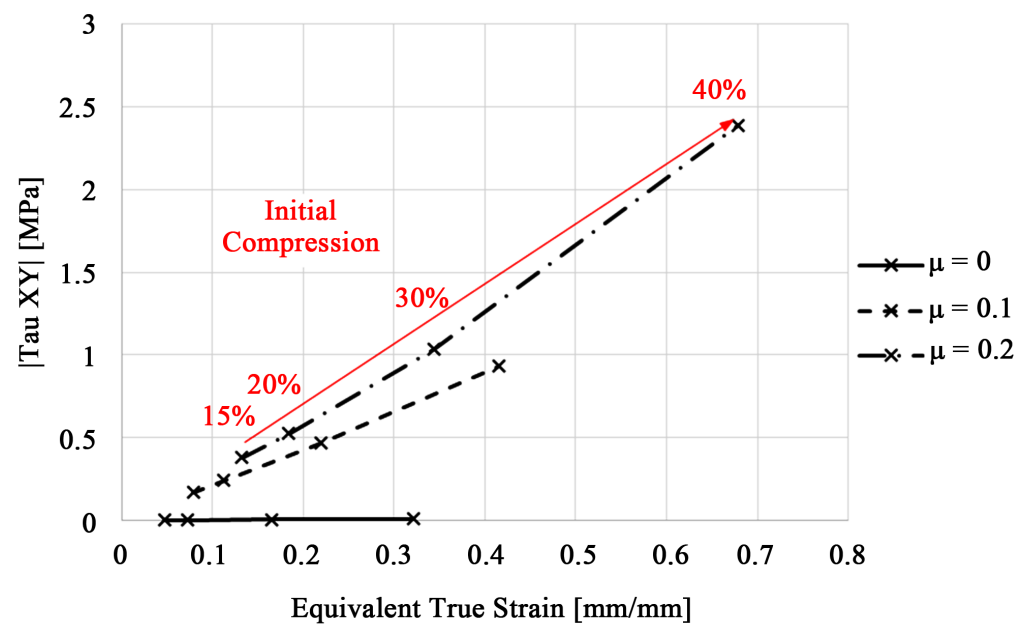

Figure 25. The shear stress in function of the initial compression and the equivalent true strain.

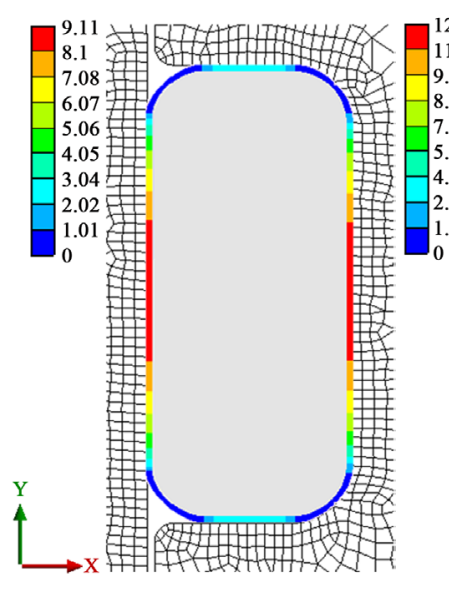

(a)

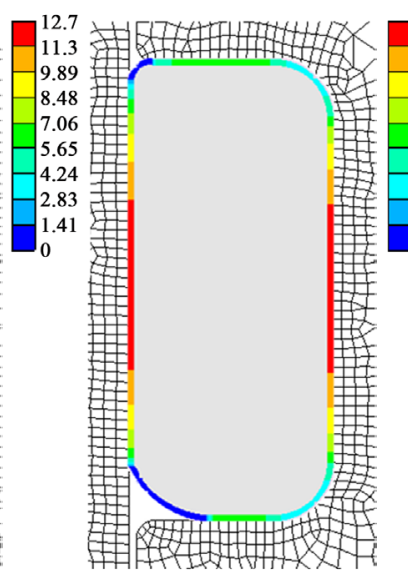

(b)

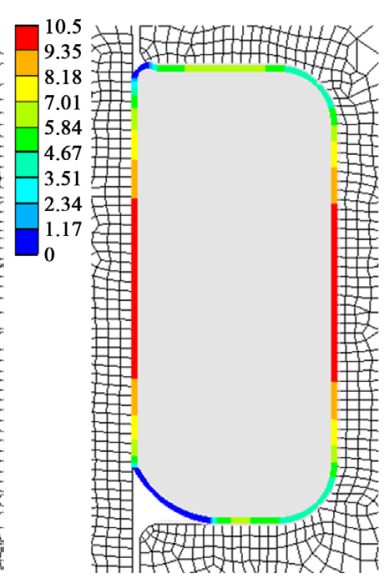

(c)

Figure 26. Contact pressure on the edge of the O-ring with $\mu=0.001$. (a) after assembly; (b) after operating pressure is applied and (c) after 1 hour of operating pressure is applied. 


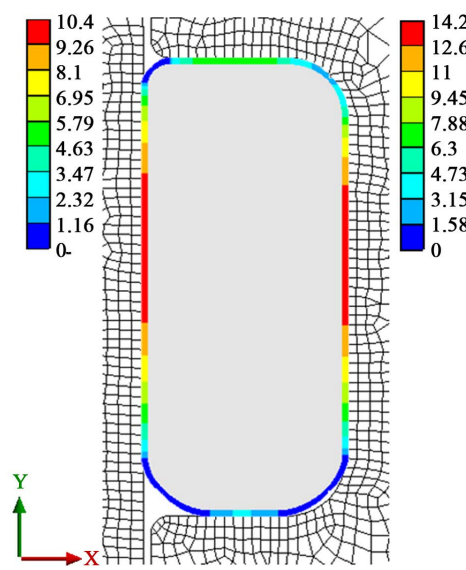

(a)

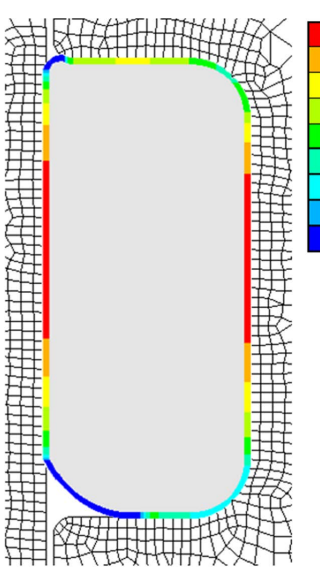

(b)

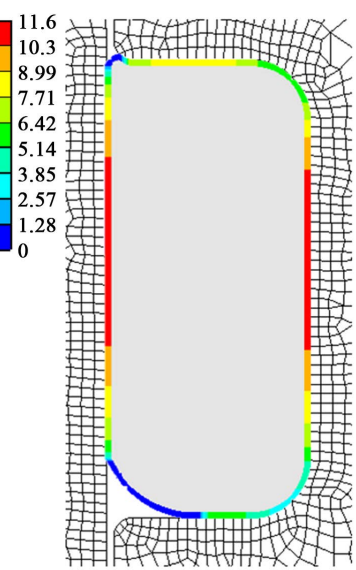

(c)

Figure 27. Contact pressure on the edge of the O-ring with $\mu=0.1$. (a) after assembly; (b) after operating pressure is applied and (c) after 1 hour of operating pressure is applied.

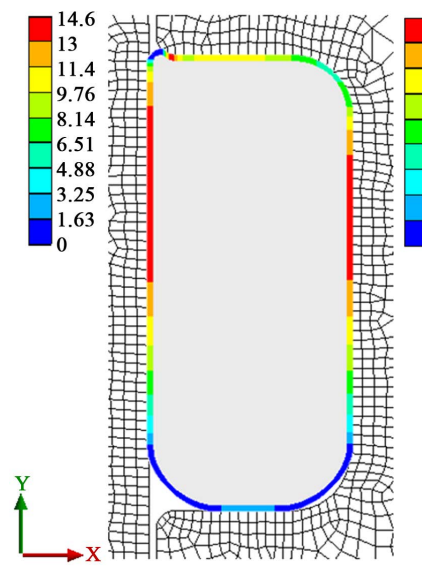

(a)

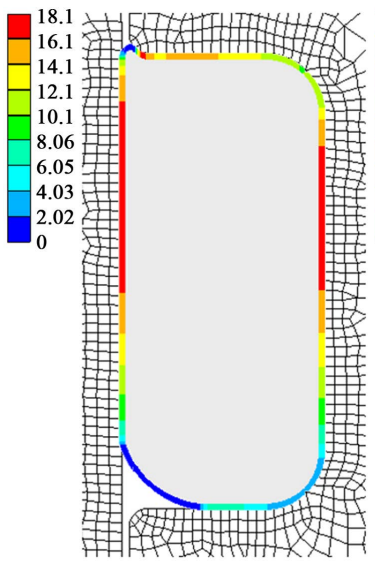

(b)

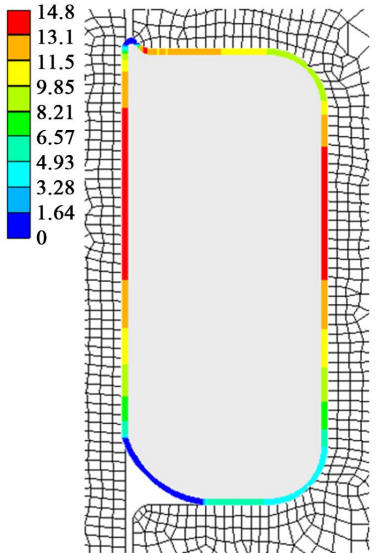

(c)

Figure 28. Contact pressure on the edge of the O-ring with $\mu=0.2$. (a) after assembly; (b) after operating pressure is applied and (c) after 1 hour of operating pressure is applied.

Figure 29 depicts the assembly process of the O-ring, when the coefficient of friction is 0.2 and the initial compression is $40 \%$. These given conditions may lead to fault during assembly, due to the too much initial compression, more material is pushed away by the shaft. The above mentioned effect and the high coefficient of friction can cause the material to be sheared off, which leads to immediate leakage [1].

\subsection{Effect of Extreme Operating Pressure}

The effect of extreme pressure was investigated for minimal sealing pressure case, with normal, $15 \%$ initial compression. The operating pressure was 100 bars instead of the 50 bars of operating pressure, which is considered to be the upper limit of O-rings without supporting ring. One can see the deformed shape and the total deformation of the seal in Figure 30 and Figure 31. Excessive penetration of the material can be found between the housing and the shaft. In the 


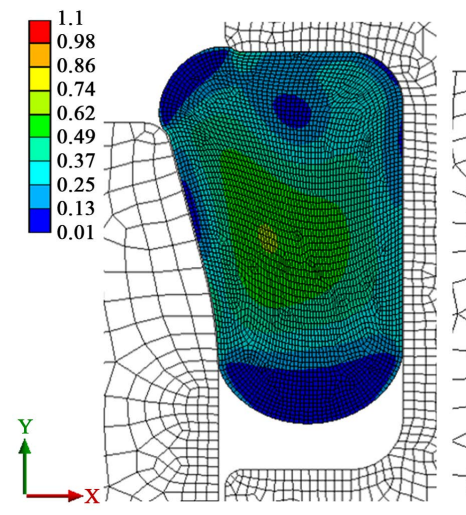

(a)

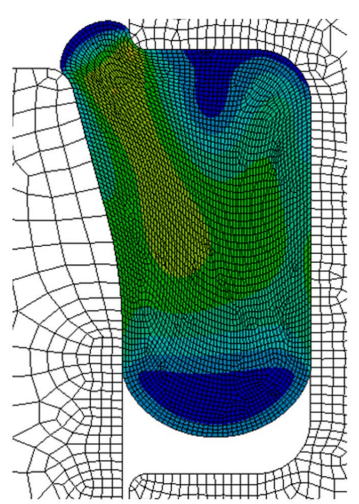

(b)

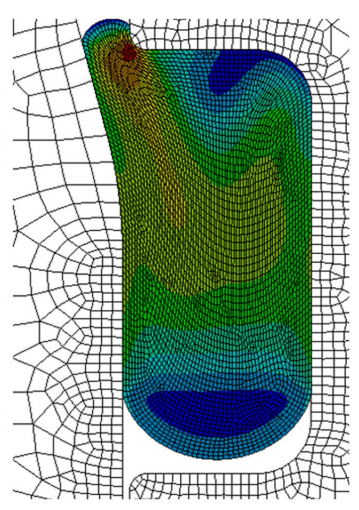

(c)

Figure 29. Occurring equivalent strain during installation, deformation scale 1:1.

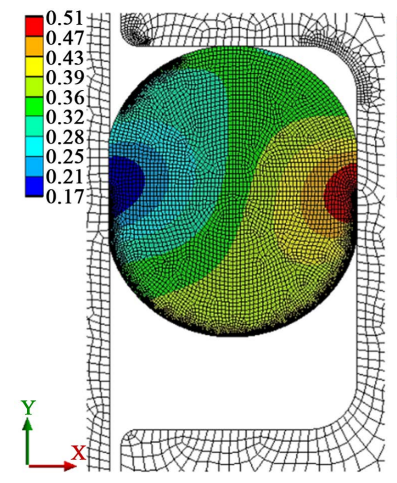

(a)

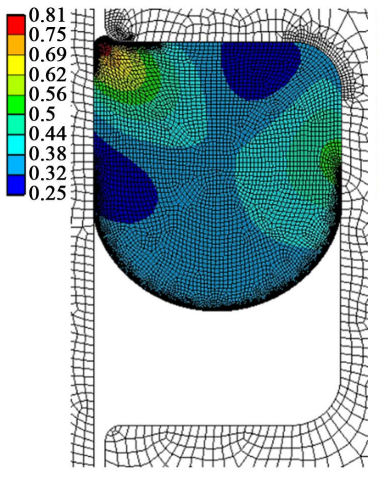

(b)

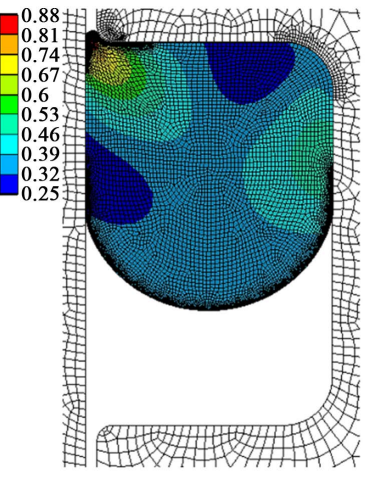

(c)

Figure 30. Total deformation of the O-ring with $\mu=0.001$. (a) after assembly; (b) after operating pressure is applied and (c) after 1 hour of operating pressure is applied.

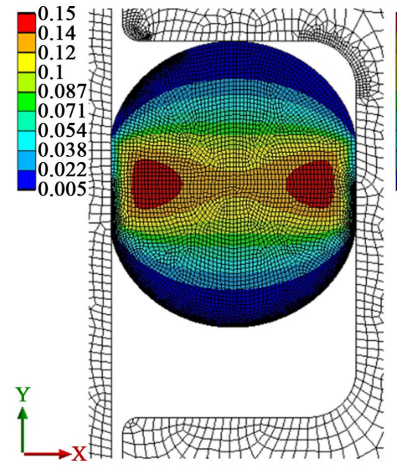

(a)

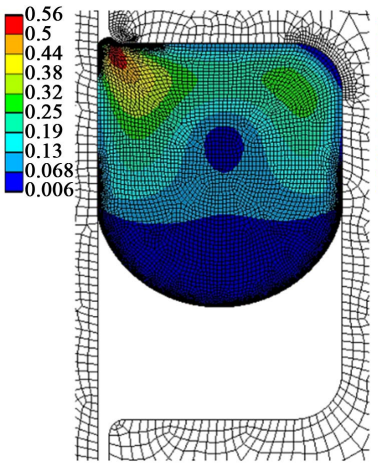

(b)

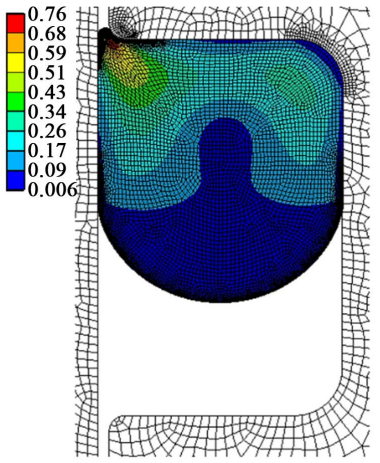

(c)

Figure 31. Equivalent elastic true strain of the O-ring with $\mu=0.001$. (a) after assembly; (b) after operating pressure is applied and (c) after 1 hour of operating pressure is applied.

absence of friction the maximal value of total deformation is $0.88 \mathrm{~mm}$ and that of the equivalent elastic true strain is $0.76 \mathrm{~mm} / \mathrm{mm}$ after one hour of operating pressure. With $\mu=0.2$ those values are $0.84 \mathrm{~mm}$ and $0.96 \mathrm{~mm} / \mathrm{mm}$ as seen in Figure 32 and Figure 33. The friction tries to prevent the material to penetrate 


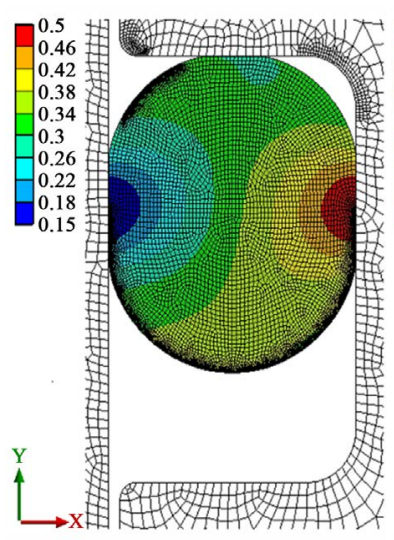

(a)

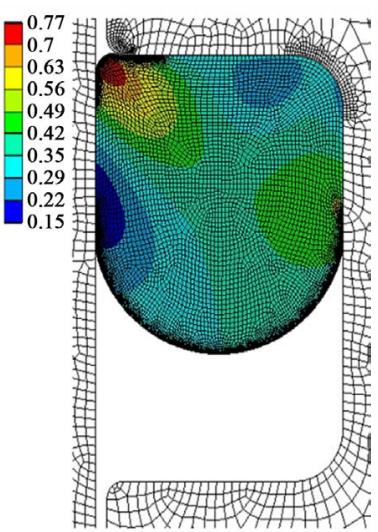

(b)

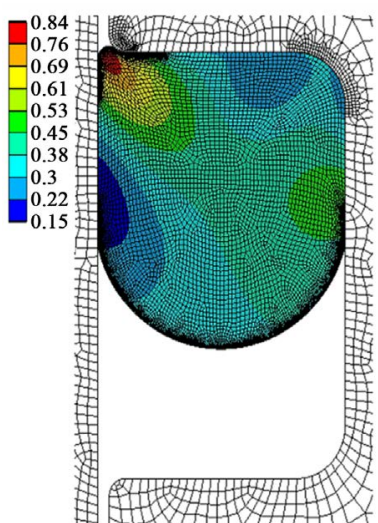

(c)

Figure 32. Total deformation of the O-ring with $\mu=0.2$. (a) after assembly; (b) after operating pressure is applied and (c) after 1 hour of operating pressure is applied.

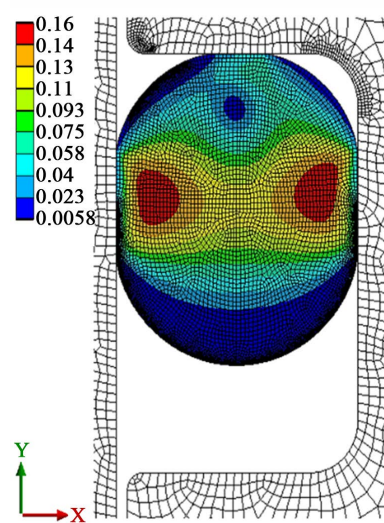

(a)

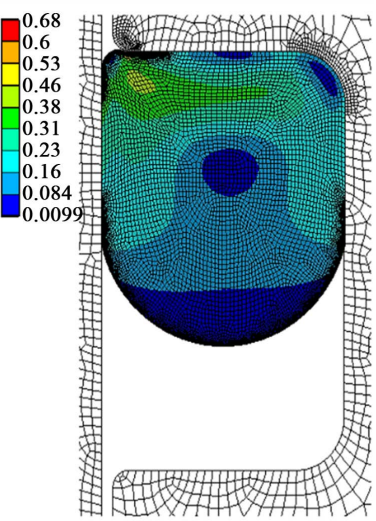

(b)

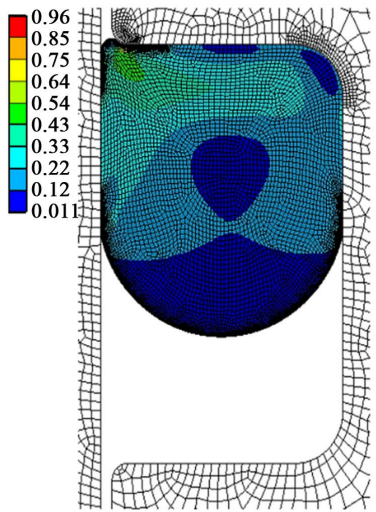

(c)

Figure 33. Equivalent elastic true strain of the O-ring with $\mu=0.2$ (a) after assembly; (b) after operating pressure is applied and (c) after 1 hour of operating pressure is applied.

into the gap, thus the lower total deformation values, although higher strain values occur due to the shear of the material. Excessive strain and shear can cause the material to crack on its' circumference under high pressure.

\subsection{Effect of Extreme Operating Temperature}

For the simulation of the extreme operating temperature's effect, the coefficient of thermal expansion for both the rubber material and the metal parts were considered in the FE model. For the steel material $1.2 \times 10^{-5} 1 /^{\circ} \mathrm{C}$, for the rubber material $11 \times 10^{-5} 1 /{ }^{\circ} \mathrm{C}$ coefficient of thermal expansion was considered. For each analysis the cooling period started at $20^{\circ} \mathrm{C}$. As the material model is time-dependent, the cooling of the O-ring was set for $10 \mathrm{~s}, 1 \mathrm{~m}, 10 \mathrm{~m}$ and for 1 hour. In real life conditions, $1 \mathrm{~h}$ corresponds to a very slow cooling, and $10 \mathrm{~s}$ is a very rapid cooling. Figure 34 shows the maximal value of the contact pressure on the inner side of the O-ring, where it is contacting with the shaft, for the different cooling periods. It can be seen, that for rapid cooling below $-50^{\circ} \mathrm{C}$ the 


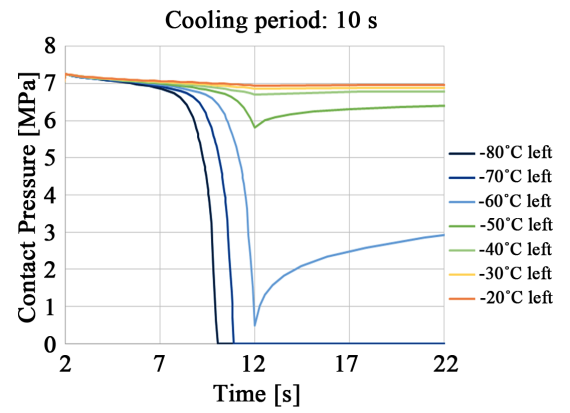

(a)

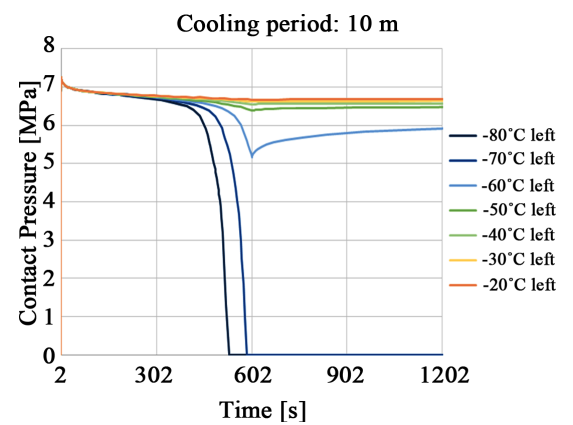

(c)

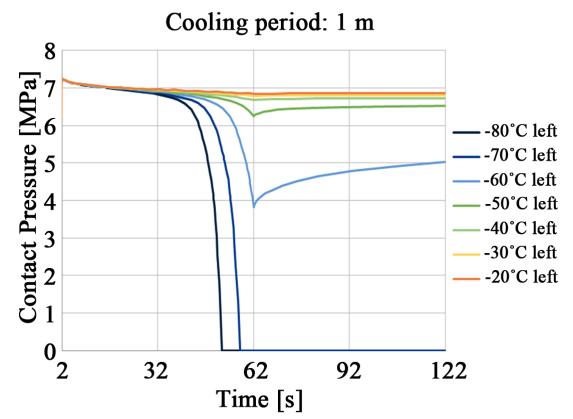

(b)

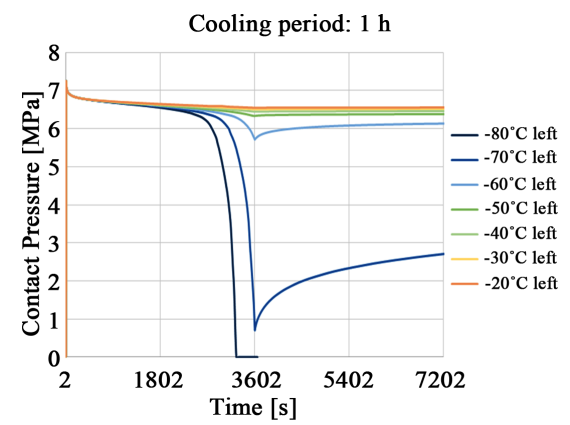

(d)

Figure 34. The maximal value of the contact pressure between the shaft and the O-ring in the case of (a) $10 \mathrm{~s}$; (b) $1 \mathrm{~m}$; (c) $10 \mathrm{~m}$; (d) $1 \mathrm{~h}$ cooling time.

sealing loses significant contact (sealing) pressure. For any lower temperature the seal fails to operate as there is no remaining sealing pressure between the shaft and the housing. This corresponds to the results of the DMTA measurements, where the stiffness of the material changes significantly under $-50^{\circ} \mathrm{C}$. Above that the material is more elastic and less stiff, so it can compensate the change of the geometry, due to thermal expansion (shrinkage) faster. For longer cooling periods the material behaves more and more soft above $-50^{\circ} \mathrm{C}$. For $1 \mathrm{~h}$ of cooling period the seal still operates at $-60^{\circ} \mathrm{C}$. At $-70^{\circ} \mathrm{C}$ hardly any pressure remain on the contact surfaces for a short time, which can cause leakage. This small amount of pressure is then rises up to a value of approximately $3 \mathrm{MPa}$, which is less than half of the value measured on room temperature. The contact pressure distribution at the end of the different cooling periods can be seen in Figure 35 at different temperatures. The values were evaluated on the inner side of the O-ring, where it touches the shaft.

Varying the cooling period, one can see, that as the time is shortened the minimal value of the contact pressure is decreasing rapidly. In Figure 36 the results at $-60^{\circ} \mathrm{C}$ are compared. For 10 seconds of cooling the contact pressure almost completely drops to zero value for a short time. Investigating an extreme case, where the cooling period is only 10 seconds, the contact pressure almost drops to zero which can cause the leakage of the seal. These results can be seen in Figure 35(a). Figure 37 shows how the contact pressure distribution changes at the end of the different cooling periods at $-60^{\circ} \mathrm{C}$. 


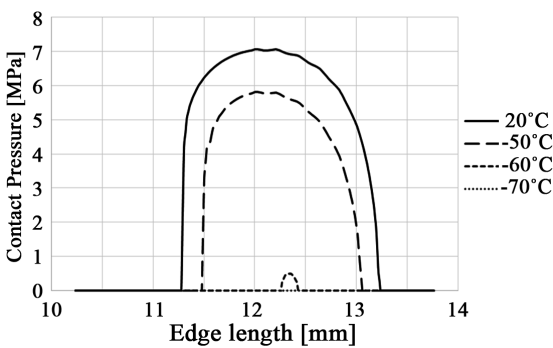

(a)

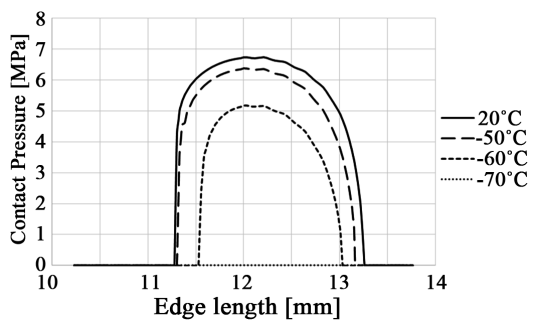

(c)

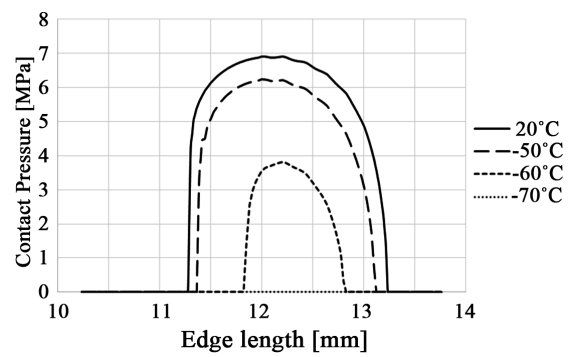

(b)

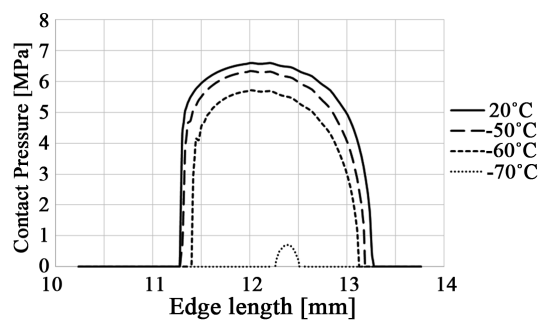

(d)

Figure 35. Contact pressure distribution between the shaft and the O-ring, in function of the temperature at the time when contact pressure is minimal for (a) $10 \mathrm{~s}$; (b) $1 \mathrm{~m}$; (c) 10 $\mathrm{m}$; (d) $1 \mathrm{~h}$ cooling time.

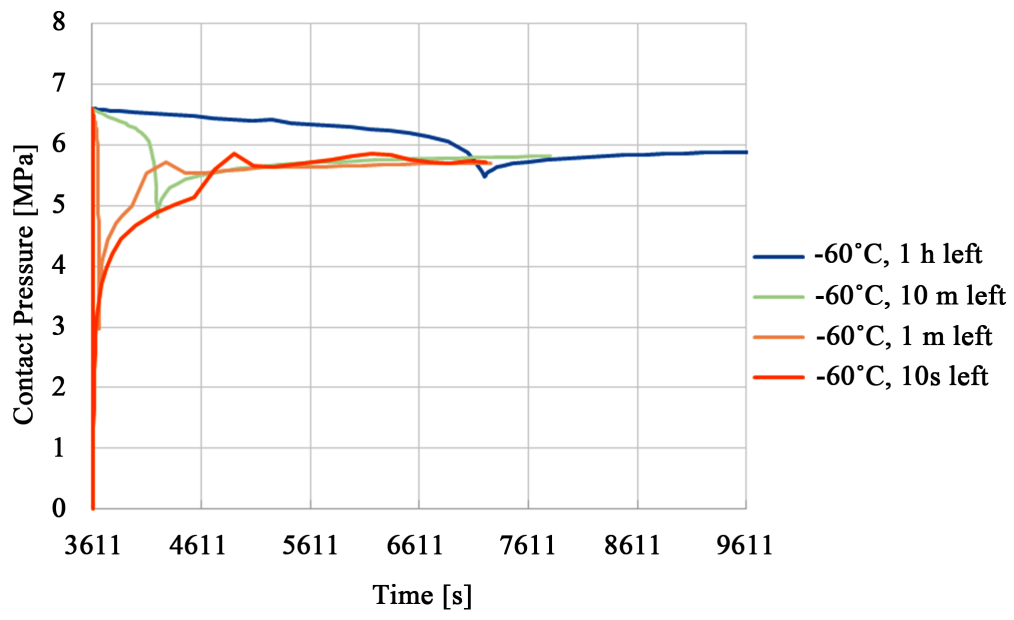

Figure 36. The maximal values of the contact pressure on both sides of the O-ring for different cooling times at $-60^{\circ} \mathrm{C}$.

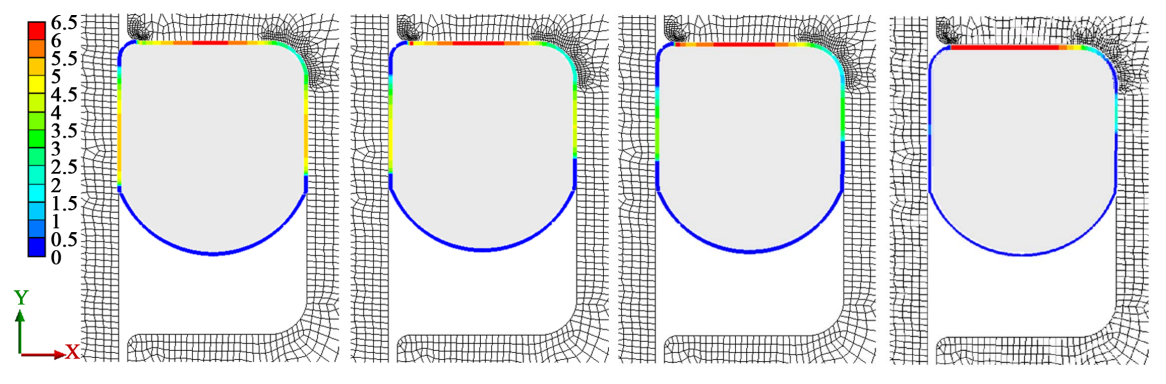

(a)

(b)

(c)

(d)

Figure 37. Contact pressure distribution at the end of the cooling period when the time of cooling was set to (a) $1 \mathrm{~h}$; (b) $10 \mathrm{~min}$; (c) $1 \mathrm{~min}$; (d) $1 \mathrm{~s}$. 


\section{Conclusions}

- With the help of the developed large-strain material model, it is possible to investigate the O-rings'-or more generally seals-behavior in normal and in extreme conditions, such as excessive initial compression, overpressure or extreme temperature.

- High initial compression of the O-rings causes large strain values on the surface of the bodies, and in function of the coefficient of friction, it results in large shear stresses. These two effects combined together cause the fail form of O-rings experienced when installing those with high initial compression, namely, developing cracks along the circumference of both sides of the O-ring. Though the same fail mechanism occurs when the O-rings are assembled with the appropriate initial compression, but they swell under the influence of oil or grease.

- Under extreme operating pressure or the lack of friction, caused by proper lubrication or vibration, the O-rings can penetrate into the gap between the housing and the shaft, where it highly distorts locally, and causes crack in radial direction experienced in practice.

- Extremely low temperatures and extremely fast cooling speeds cause untightness of the system, resulting leakage. Cooling down the seal in 1 minute at $-60^{\circ} \mathrm{C}$, it loses half of the contact (sealing) pressure and at $-70^{\circ} \mathrm{C}$ it completely fails to seal. For any slower cooling speeds the seal is capable of compensating the thermal expansion induced deformation of the bodies, but for any faster cooling speeds, the O-ring fails to operate.

\section{References}

[1] Marco Rubber \& Plastics Products Inc. (2009) O-Ring Failure Analysis. https://www.marcorubber.com/o-ring-troubleshooting.htm

[2] Bernhard, R. (2016) Why O-Rings Fail-Several O-Ring Failure Modes for O-Rings and Their Causes. O-Ring Prüflabor Richter.

[3] ISO 37:2011. Rubber, Vulcanized or Thermoplastic-Determination of Tensile Stress-Strain Properties.

[4] Vezér, S. and Major, Z. (2008) Development of an In-Plane Biaxial Test Setup for Monotonic and Cyclic Test for Elastomers. 25th Danubia-Adria Symposium on Advances in Experimental Mechanics, Budweis, 2-27 September 2008.

[5] Day, J.R. and Miller, K.A. (2000) Equibiaxial Stretching of Elastomeric Sheets: An Analytical Verification of Experimental Technique. ABAQUS User's Conference Proceedings, Newport, 30 May-2 June 2000, 205-220.

[6] Axel Products Inc. Testing Brief: Compression or Biaxial Extension? http://www.axelproducts.com/downloads/CompressionOrBiax.pdf

[7] Menard, K.P. (1999) Dynamic Mechanical Analysis: A Practical Introduction. CLC Press, Boca Raton. https://doi.org/10.1201/9781420049183

[8] Szabó, Gy. and Váradi, K. (2018) Large Strain Viscoelastic Material Models for Deformation, Stress and Strain Analysis of O-Rings. Periodica Polytechnica.

[9] ANSYS Inc. (2016) ANSYS Help 17.2. Canonsburg. 